DOI: 10.2478/awutp-2018-0002

\title{
IMPROVED MODEL FOR FORECASTING GLOBAL SOLAR IRRADIANCE DURING SUNNY AND CLOUDY DAYS
}

\author{
Bogdan-Gabriel Burduhos, Mircea Neagoe*
}

Renewable Energy Systems and Recycling (RESREC) Centre, Transilvania University of Brasov, Romania *mneagoe@unitbv.ro

\begin{tabular}{|l|l|}
\hline \multicolumn{1}{|c|}{ Article Info } & \multicolumn{1}{c|}{ Abstract } \\
\hline Received: 18.03 .2018 & \multicolumn{1}{c|}{ A precise estimation of the electrical energy produced daily by photovoltaic } \\
Accepted: 14.06 .2018 & $\begin{array}{l}\text { (PV) systems is important both for PV owners and for electrical grid operators. It } \\
\text { can be achieved if the received solar irradiance can be accurately estimated during } \\
\text { any type of daily solar profile (clear, cloudy, mixed sky), not only average solar } \\
\text { Keywords: solar } \\
\text { profile for larger periods of time, e.g. one month or season, as used in PV system } \\
\text { design. The paper firstly describes an existing mathematical model, based on the } \\
\text { global/direct/diffuse } \\
\text { irradiance, clear/cloudy } \\
\text { sky. }\end{array}$ \\
$\begin{array}{l}\text { Meliss approach, which uses mean monthly coefficients for estimating average } \\
\text { direct and diffuse solar irradiance. This model is satisfactory for monthly / annual } \\
\text { intervals but is not useful for daily estimations. Therefore in the second part of the } \\
\text { paper an algorithm which allows to generate daily variations of the model's } \\
\text { coefficients for clear and cloudy sky conditions is proposed. The improved model } \\
\text { with variable coefficients was tested during several representative days and can be } \\
\text { used for estimating the effect which different meteorological conditions as } \\
\text { fog/dew/frost have on the quantity and quality of the solar irradiance received by a } \\
\text { PV convertor. }\end{array}$ \\
\hline
\end{tabular}

\section{Introduction}

In the near future the nZEB (Nearly Zero Energy Building) concept will be highly implemented in new buildings and communities, according to the Energy Performance of Buildings Directive (EPBD) [1]. This directive asks for at least $50 \%$ of the building energy demand to be covered using renewable energy systems (RES) installed either on or near the building $[2,4]$ and for buildings with higher energy efficiency.

Photovoltaic (PV) systems are considered one of the best solutions for producing electrical energy in the built environment [5]. However, the electrical energy to be produced during a day can be hardly estimated since it depends mainly on the available solar irradiance and other local meteorological phenomena like fog/dew/frost. 
A good predictability of the daily produced electrical energy is important both for owners of PV systems, and for DSOs (distribution system operators), TSOs (transmission system operators) and PV aggregators participating in the electricity markets, since they are responsible for balancing the grid.

The previously mentioned meteorological phenomena (fog/dew/frost) are a consequence of specific pressure-temperature-humidity-wind conditions and can occur both during clear and cloudy sky conditions (Fig. 1). They mainly influence the solar irradiance quantity received on a photovoltaic surface, but also its quality, indicated by the ratio between direct and diffuse irradiance. This influence can be described, as indicated in Fig. 1, by pairs of irradiance coefficients $F_{C C}$ and $C_{D}$ ( $n$ - cloudy, $s$ - clear sky and $f d f-$ fog/dew/frost), which are further detailed in the next chapter.

In order to be able to predict solar irradiance during intervals with mentioned weather phenomena the following information should be known:

- the temperature and relative humidity of the air, the atmospheric pressure and the wind speed, based on which the type of the weather phenomenon can be stated;

- the available solar irradiance, measured during the observed phenomenon;

- the mathematical models adapted to the implementation location using solar irradiance data from at least 1 year, able to predict the direct and diffuse solar irradiance during clear and cloudy sky conditions.

The difference between the modeled and measured irradiance values can be used to estimate the influence of each weather phenomenon on the received solar irradiance.

This paper focuses on the third aspect, trying to improve an existing solar irradiance estimation model to be used during clear and cloudy sky conditions, without meteorological phenomena like fog/dew/frost (Fig. 1a and b).

\section{Problem formulation and infrastructure description}

Available solar irradiance at the surface of the Earth has mainly two components: direct (beam) solar irradiance, $B$, and diffuse irradiance, $D$. Their sum, measured or calculated in the same plane, $x$, represents the global solar irradiance, $G_{x}=B_{x}+D_{x}$. 


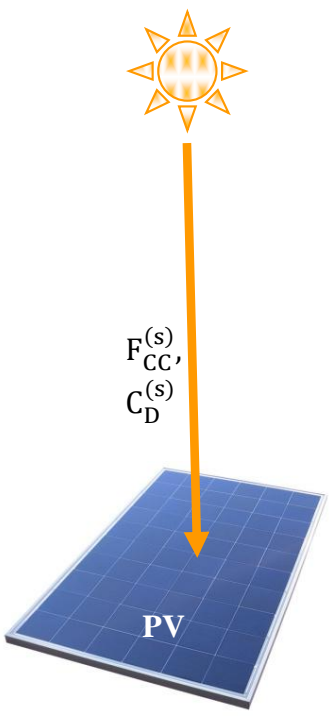

a)

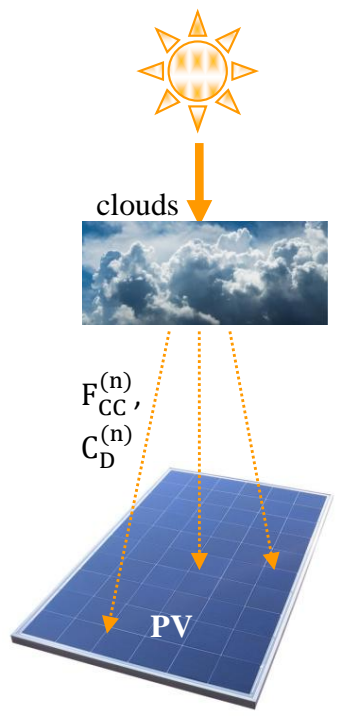

b)

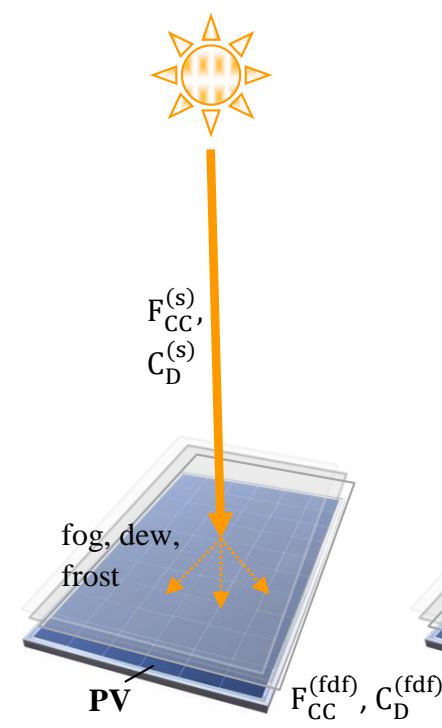

c)

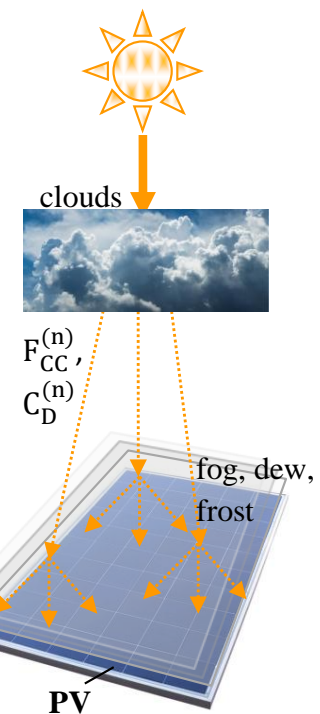

d)

Fig. 1. Possible meteorological conditions for the operation of a PV module: a) clear sky, b) cloudy sky, c) clear sky with fog/dew/frost, d) cloudy sky with fog/dew/frost.

According to the German meteorological school (the Meliss model [6]), under ideal clear sky conditions the direct solar irradiance received at ground level can be estimated using Eq. (1), while the diffuse solar irradiance in the horizontal plane using Eq. (2):

$$
\begin{gathered}
B=B_{0} \exp \left(-\frac{T_{R}}{0.9+9.4 \sin \alpha}\right), \\
D_{H}=1 / 3\left(B_{0}-B\right) \sin \alpha,
\end{gathered}
$$

where $\alpha$ is the altitude angle of the Sun, depicted in Fig. 2, $T_{R}$ is the Linke turbidity factor with monthly values specific to the location where the irradiance is estimated [6], and $B_{0}$ is the extraterrestrial solar irradiance, Eq. (3):

$$
B_{0}=1367 \cdot\left[1+0.0334 \cdot \cos \left(0.9856^{\circ} \cdot N-2.72^{\circ}\right)\right]
$$

where $N$ is the day number in the year. 


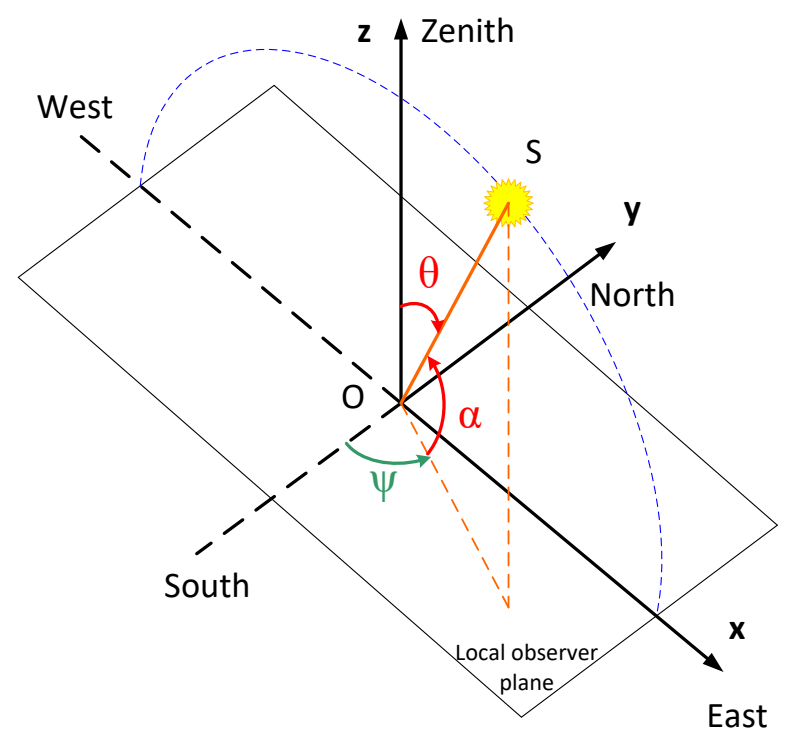

Fig. 2. Local solar altitude $(\alpha)$ and azimuth $(\psi)$ angles in the local observer frame $(\theta-$ solar zenith angle $)[7]$.

The Meliss model was improved by researchers from the Transilvania University of Brasov $[8,9]$, in order to cope with non-ideal clear sky conditions and monthly variation of the two types of irradiance, specific to the conditions of Brasov, Romania. Thus, a factor of cloud crossing $\left(F_{c c}\right)$-was introduced (Eq. (4)) indicating the average cloud coverage specific for different sky conditions (clear, cloudy or partially clouded sky) during a specified time period, and allowing a better estimation of direct solar irradiance under non-ideal conditions:

$$
B=F_{C C} \cdot B_{0} \exp \left(-\frac{T_{R}}{0.9+9.4 \sin \alpha}\right)
$$

If the direct beam solar irradiance, $B$, is known (measured or estimated) the direct solar irradiance incident on a horizontal plane, $B_{H}$, can be easily calculated using the Lambert relation, Eq. (5). This type of irradiance is also called direct normal irradiance (DNI) and represents a good indicator in literature for solar irradiance potential of a location.

$$
B_{H}=B \cdot \sin \alpha
$$

For the diffuse solar irradiance, which is maximal in the horizontal plane, the $1 / 3$ constant of the Meliss model was replaced with the $C_{D}$ correction factor, which depends on the real meteorological conditions of the considered location: 


$$
D_{H}=C_{D} \cdot\left(B_{0}-B\right) \sin \alpha,
$$

For both correction factors of the solar irradiance, $F_{c c}$ and $C_{D}$, mean monthly constant values were calculated for the location Brasov, Romania using horizontal solar irradiance data $\left(G_{H}\right.$ and $\left.D_{H}\right)$ measured during the interval 2006..2011 [9]. Similar correction factors can be obtained for any other location if preliminary solar irradiance data is available and the steps described in [9] are followed.

The mean monthly values allow a good estimation of the annually / monthly available solar irradiance and also during medium days with partially clouded sky, but during clear sky or cloudy days and especially for hourly / instantaneous estimation of the solar irradiance these values are not useful. As an example, Fig. 3 and Table 1 present the results of using mean monthly constant values of the $F_{c c}$ and $C_{D}$ coefficients during three types of days: clearsky (13 ${ }^{\text {th }}$ May 2006), cloudy-sky (18 ${ }^{\text {th }}$ May 2006) and mixed-sky days (21 ${ }^{\text {st }}$ May 2006). As observed in Table 1 the model with mean coefficients underestimates with $26 \%$ the available solar irradiance during the clear-sky day, overestimates very much (335.7\%) during the cloudy-sky day and overestimates with $30.8 \%$ the mixed sky day.

For forcasting daily variation of the solar irradiance, instantaneous values of the correction coefficients should be used, calculated according to the type of day: clear sky day $F_{C C}^{(s)}$ and $C_{D}^{(s)}$, respectively cloudy sky day $-F_{C C}^{(n)}$ and $C_{D}^{(n)}$ and useful if the sky cloud coverage is known. The needed steps and the results of these parameters are presented further on in this paper.

Table 1. Energy of the incident solar irradiance measured and estimated using mean monthly constant values of the $\mathrm{F}_{\mathrm{CC}}$ and $\mathrm{C}_{\mathrm{D}}$ correction coefficients.

\begin{tabular}{c|c|c|c}
\hline & $\begin{array}{c}\text { May 13 } \\
\text { Clear sky }\end{array}$ & $\begin{array}{c}\text { May } \mathbf{1 8}^{\text {th }} \mathbf{2 0 0 6} \\
\text { Cloudy sky }\end{array}$ & $\begin{array}{c}\text { May 21 } \\
\text { Mixed 2006 }\end{array}$ \\
\hline$E\left(G_{H \_}\right.$measured $)\left[\mathrm{Wh} / \mathrm{m}^{2} /\right.$ day $]$ & 6679 & 1155 & 3882 \\
\hline$E\left(G_{H \_}\right.$estimated $F_{C C}$ and $\left.C_{D}\right)$ & 4944 & 5032 & 5077 \\
$\left[\mathrm{Wh} / \mathrm{m}^{2} /\right.$ day $] \quad$ (relative error $)$ & $(-26.0 \%)$ & $(+335.7 \%)$ & $(+30.8 \%)$ \\
\hline
\end{tabular}



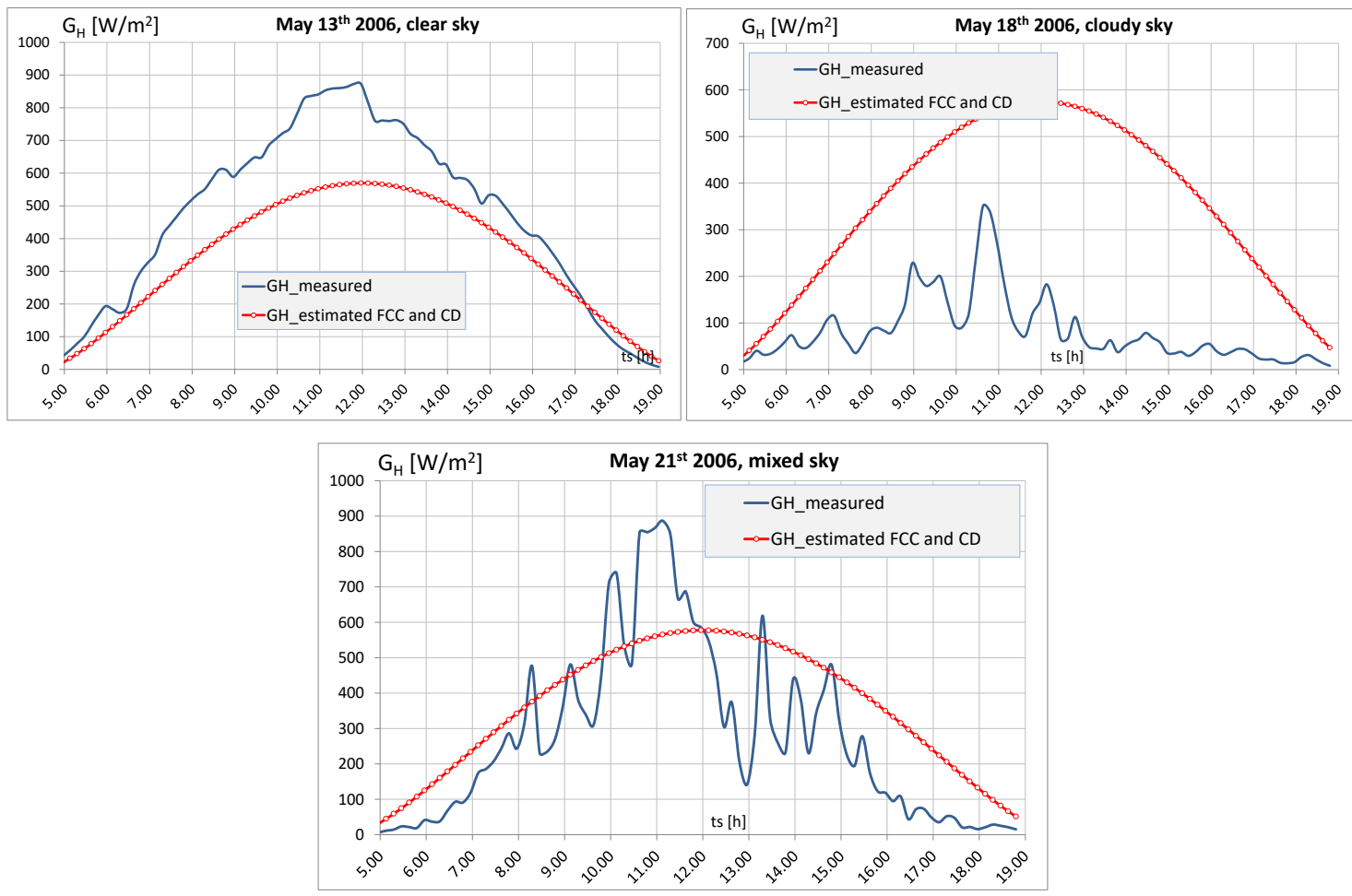

Fig. 3. Comparison between measured and estimated irradiance using mean monthly constant values of the $F_{\mathrm{CC}}$ and $\mathrm{C}_{\mathrm{D}}$ coefficients during three representative types of days.

The equipment used in the Research Center Renewable Energy Systems and Recycling for monitoring solar irradiance and estimating local correction coefficients is a combined pyranometer, type DeltaT - SPN1 (Fig. 4), able to measure both global and diffuse horizontal irradiance, installed on the terrace of the building $\mathrm{E}$, in the Colina university campus.

The pyranometer is connected to a DeltaT DL2e weather station (Fig. 5) also able to monitor local meteorological parameters such as: sunshine duration, wind speed and direction, air temperature, relative air humidity and quantity of liquid rainfall.

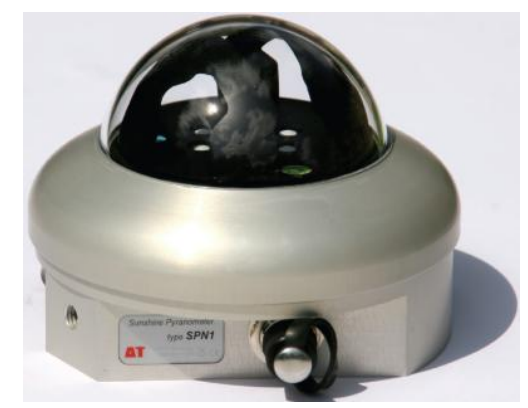

Fig. 4. DeltaT SPN1 pyramometer used for measuring direct and diffuse solar irradiance in the horizontal plane.

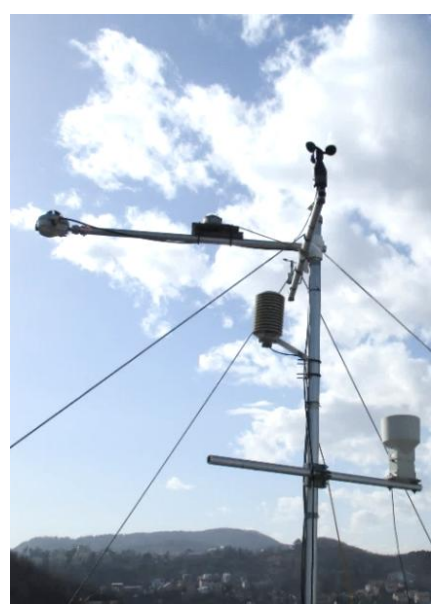

Fig. 5. DeltaT DL2e meteorological weather station at the Transilvania University of Brasov 


\section{Method and results}

In order to obtain daily usable solar irradiance estimations, the values of the two correction coefficients $F_{C C}$ and $C_{D}$, under the two main meteorological conditions (clear and cloudy sky), were generated in this paper using the following steps:

1. From the same month of each year the data measured only during clear sky days $\left(k=D_{H} / G_{H}<0.25\right)$ and respectively completely cloud covered sky $(k>0.9)$ [3], are selected;

2. The profile of the equivalent day associated to the selected days can be identified using average irradiance values $\left(D_{H e}, G_{H e}\right)$;

3. The equivalent direct solar irradiance is calculated $B_{e}=B_{H e} / \sin \alpha=\left(G_{H e}-D_{H e}\right) / \sin \alpha$;

4. The daily variation of the $F_{C C}^{(s)}$ coefficient (respectively $F_{C C}^{(n)}$ ) during the equivalent sunny day can be obtained by solving Eq. (4), where $B=B_{e}, B_{0}=B_{0 e}, \alpha=\alpha_{e}$ and $T_{R}$ was used with the monthly average values indicated in [9];

5. The daily variation of the $C_{D}^{(s)}$ coefficient (respectively $C_{D}^{(n)}$ ) during the equivalent cloudy day can be obtained by solving Eq. (6), where $B=B_{e}$ and $D_{H}=D_{H e}$;

All equivalent values discussed above are obtained as the mean arithmetical values of the correspondent parameter, during different days, but at the same solar time.

The obtained values of the $F_{C C}$ and the $C_{D}$ coefficient can be approximated, if the solar time is known, using $3^{\text {rd }}$ grade interpolation functions during clear sky days and linear interpolation functions during cloudy days. These approximation functions may also support daily proportional adjustments according to the conditions of very near antecedent days.

The numerical results and the interpolation functions used for the daily approximation of the two correction coefficients, are presented in Fig. 6 for the Brasov location, Romania.

The good estimation of global horizontal irradiance values using the improved $F_{C C}$ and $C_{D}$ correction coefficients is indicated by the exemplificative daily diagrams from Fig. 6 and by the numeric results from Table 2, where two different day types from the year 2012 are analyzed. During the clear-sky day $\left(22^{\text {nd }}\right.$ July 2012$)$ the available solar irradiance is underestimated with $7.4 \%$ compared to $30.8 \%$ when using mean monthly coefficients, while during the cloudy day $\left(14^{\text {th }}\right.$ October 2012$)$ the irradiance is underestimated with $5.5 \%$ compared to the an overestimation of $315 \%$ with using mean monthly coefficients. 
Table 2. Energy of the incident solar irradiance measured and estimated using improved instantaneous values and monthly mean values of the correction coefficients.

\begin{tabular}{c|c|c}
\hline & $\begin{array}{c}\text { July 22 } \\
\text { Clear sky }\end{array}$ & $\begin{array}{c}\text { Oct 14 } \\
\text { Cloudy sky }\end{array}$ \\
\hline$E\left(G_{H \_}\right.$measured $)\left[\mathrm{Wh} / \mathrm{m}^{\text {th }} /\right.$ day $]$ & 7894 & 583 \\
\hline$E\left(G_{H \_}\right.$estimated $F_{C C}^{(x)}$ and $\left.C_{D}^{(x)}\right), x=s, n$ & 7313 & 552 \\
{$\left[\mathrm{Wh} / \mathrm{m}^{2} /\right.$ day $]$} & $(-7.4 \%)$ & $(-5.5 \%)$ \\
\hline $\mathrm{E}\left(G_{H \_}\right.$estimated $F_{C C}$ and $\left.C_{D}\right)$ & (relative error) & 5465 \\
{$\left[\mathrm{Wh} / \mathrm{m}^{2} /\right.$ day $]$} & $(-30.8 \%)$ & $(+315 \%)$ \\
\hline
\end{tabular}
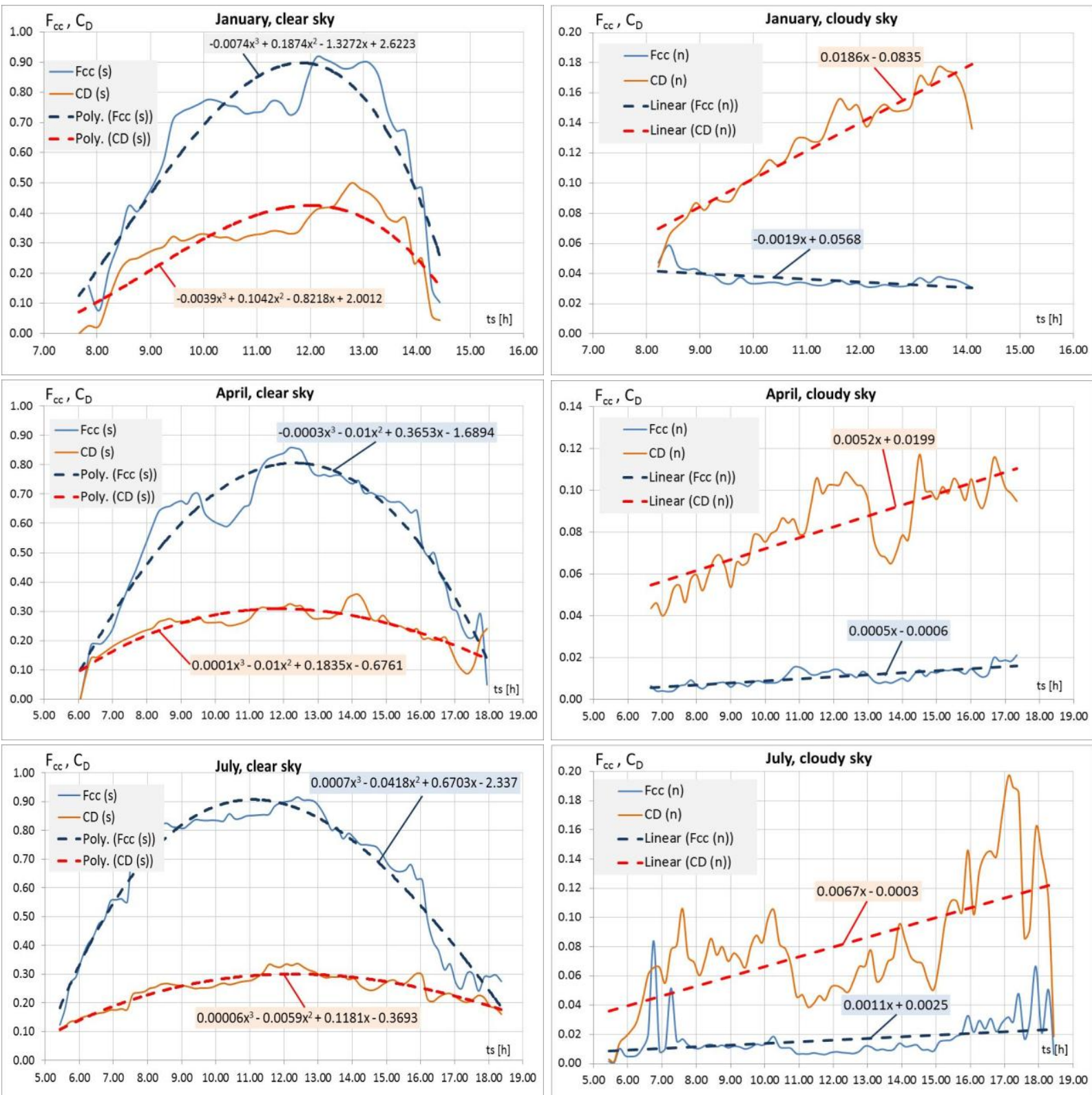

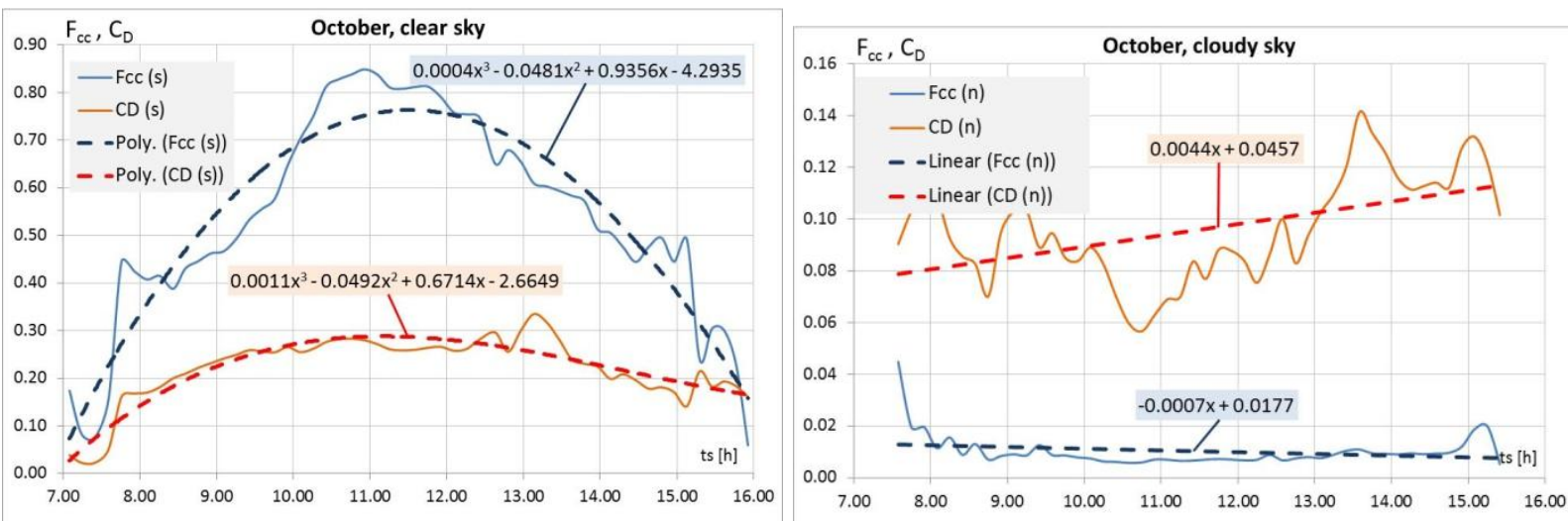

Fig. 6. Variation of the correction coefficients $\mathrm{F}_{\mathrm{CC}}$ and $\mathrm{C}_{\mathrm{D}}$ during the equivalent day of four representative months, under clear and cloudy sky conditions.

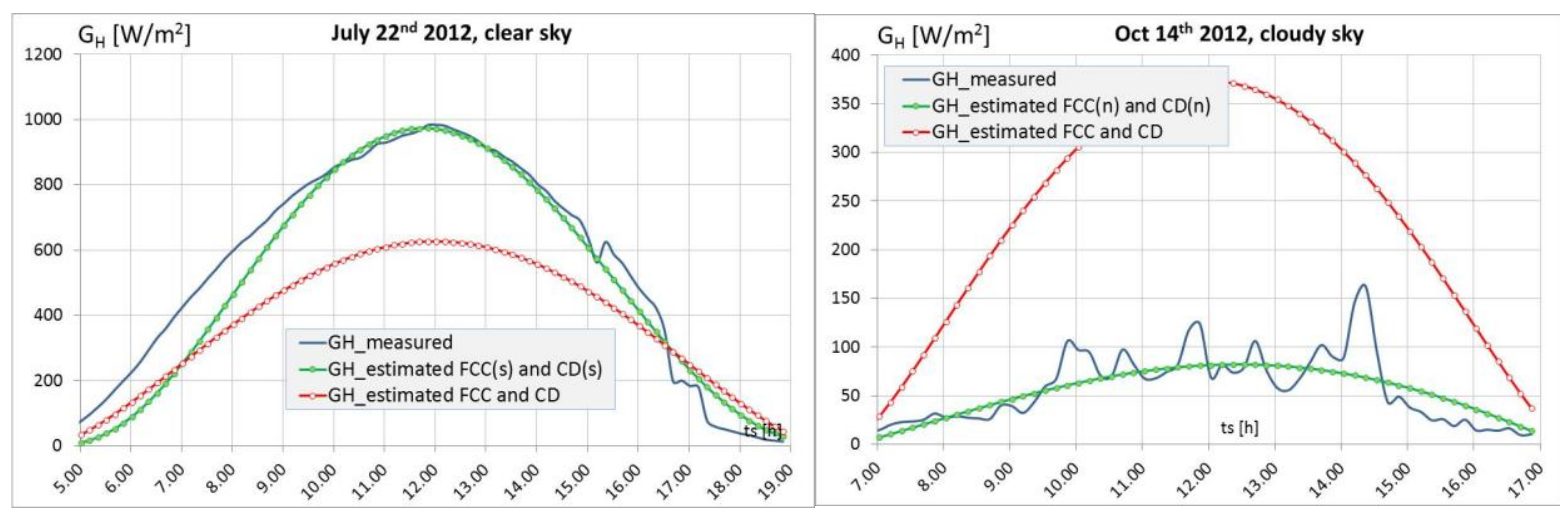

Fig. 7. Comparison between measured and estimated irradiance using improved vs. monthly constant values of the $\mathrm{F}_{\mathrm{CC}}$ and $\mathrm{C}_{\mathrm{D}}$ coefficients.

\section{Conclusions}

Using monthly constant values of the turbidity factor $T_{R}$ the following conclusions can be stated about the $F_{C C}$ and $C_{D}$ coefficients:

- during clear sky days, the $F_{C C}(s)$ and $C_{D}(s)$ coefficients have a parabolic dependence on the solar time, with maximal values during noon time $\left(0.7 \ldots 0.9\right.$ for $F_{C C}$ and $0.3 \ldots 0.4$ for $C_{D}$ ), with higher values during the cold intervals of the year;

- during cloudy days, the $F_{C C}(n)$ and $C_{D}(n)$ coefficients can be approximated with a linear function depending on the solar time, relative constant for the $F_{C C}$ (with maximum values between $0.01 \ldots 0.04$ ) and generally rising for the $C_{D}$ coefficient (with maximum values between $0.08 \ldots 0.18$ ).

With the help of the described estimation model and the improved values of the $F_{C C}$ and $C_{D}$ correction coefficients, the available solar irradiance can be well estimated depending on the date and time, for clear and cloudy skies situations. 
The same method can also be used for estimating solar irradiance during mixt days if the cloudiness of the sky and the relation between this parameter and the two correction coefficients $\left(F_{C C}\right.$ and $\left.C_{D}\right)$ can be estimated. This aspect is to be further analyzed in future studies.

Based on solar irradiance measurements at the same date and time, during intervals with fog/dew/frost the influence of these phenomena can be calculated on the quantity and quality of the solar irradiance received on a surface.

\section{References}

[1] ***, The Directive 2010/31/EU of the European Parliament and of the Council of 19 May 2010 on the energy performance of buildings, Official Journal of the European Union, 53 (2010).

[2] Aelenei L., Gonçalves H., From solar building design to Net Zero Energy buildings: Performance insights of an office building, Energy Procedia, 48 (2014), 1236-1243.

[3] Burduhos B.G., Neagoe M., Duta A., Adaptive Stepwise Orientation Algorithm for Non-concentrated Dual-Axis Solar Tracking Systems, Proc. of 14th World Congress in Mechanism and Machine Science, Taipei, Taiwan, DOI 10.6567/IFToMM.14TH.WC.OS16.006, (2015).

[4] Frontini F., Manfren M., Tagliabue L.C., A case study of solar technologies adoption: criteria for BIPV integration in sensitive built environment, Energy Procedia, 30 (2012), 1006-1015.

[5] Hassoun Anwar, Dincer Ibrahim, Development of power system designs for a net zero energy house, Energy and Buildings, 73 (2014), 120-129.

[6] Meliss M., Regenerative Energie-Quellen Praktikum, Springer, Berlin (1997).

[7] Vișa I., Jaliu C.I., Duță A., Neagoe M., Comșiț M., Moldovan M.D., Ciobanu D., Burduhos B.G., Săulescu R.G., The Role of Mechanisms in Sustainable Energy Systems, ISBN 978-606-19-0571-3, Transilvania University Press, Brasov (2015).

[8] Vișa I., Diaconescu D.V., Popa V.M., Burduhos B.G., Quantitative Estimation of the Solar Radiation Loss in the Braşov Area, Environmental Engineering and Management Journal, 8(4), (2009), 843-848.

[9] Vătășescu M.M., Moldovan M.D., Burduhos B.G., Linkages for solar tracking (in Romanian), ISBN 978-973-598-946-0, Transilvania University Press, Brasov (2011). 